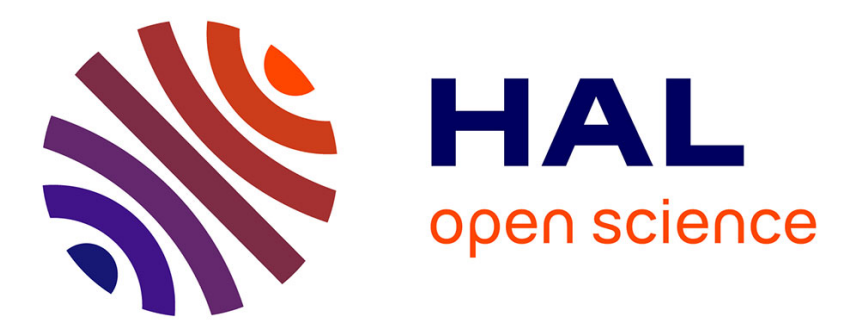

\title{
A Preliminary Study of Models for Manufacturing (MfM) Applied to Incremental Sheet Forming
}

Domingo Morales-Palma, Fernando Mas, Jesus Racero, Carpóforo Vallellano

\section{To cite this version:}

Domingo Morales-Palma, Fernando Mas, Jesus Racero, Carpóforo Vallellano. A Preliminary Study of Models for Manufacturing (MfM) Applied to Incremental Sheet Forming. 15th IFIP International Conference on Product Lifecycle Management (PLM), Jul 2018, Turin, Italy. pp.284-293, 10.1007/978-3-030-01614-2_26. hal-02075626

\section{HAL Id: hal-02075626 \\ https://hal.inria.fr/hal-02075626}

Submitted on 21 Mar 2019

HAL is a multi-disciplinary open access archive for the deposit and dissemination of scientific research documents, whether they are published or not. The documents may come from teaching and research institutions in France or abroad, or from public or private research centers.
L'archive ouverte pluridisciplinaire HAL, est destinée au dépôt et à la diffusion de documents scientifiques de niveau recherche, publiés ou non, émanant des établissements d'enseignement et de recherche français ou étrangers, des laboratoires publics ou privés.

\section{(c)(1)}

Distributed under a Creative Commons Attribution| 4.0 International License 


\title{
A preliminary study of Models for Manufacturing (MfM) applied to Incremental Sheet Forming
}

\author{
Domingo Morales-Palma ${ }^{1}$, Fernando Mas $^{2}$, Jesús Racero ${ }^{1}$, Carpóforo Vallellano ${ }^{1}$ \\ ${ }^{1}$ Universidad de Sevilla, Sevilla, Spain \\ ${ }^{2}$ Airbus, Sevilla, Spain \\ dmpalma@us.es, fernando.masdairbus.com, jrmeus.es, \\ carpoforeus.es
}

\begin{abstract}
Models for Manufacturing is a new approach proposed by the authors to apply Model-based Systems Engineering concepts to Manufacturing. The methodology under development is supported by a 3-layer framework (referred to as Data Base and Interfaces, Ontology and Software Tools layers) and simple and easy-to-use software tools. This work presents a preliminary implementation of Models for Manufacturing to SPIF, an innovative incremental sheet forming that makes use of $\mathrm{CNC}$ technology and usually requires a numerical study to validate the manufacturing process. The work introduces the proposed methodology and presents the model in development with special emphasis on the Ontology layer.
\end{abstract}

Keywords: Models for manufacturing (MfM), Model-based systems engineering (MBSE), Ontologies, Manufacturing process modelling, Single-point incremental forming (SPIF)

\section{Introduction}

Model-based Systems Engineering (MBSE) is a methodology that uses computer aided graphical modelling authoring tools to design and simulate complex systems and specify their functions and behaviours. MBSE has emerged as a viable method for multidisciplinary collaboration of stakeholders, communication of ideas and increase of productivity and quality [1]. MBSE results in models and their associated behavioural abstraction that enable more robust systems engineering [2]. MBSE has conducted several works in the aerospace and automotive industry during the last few years [3], with hundreds of developments focused in Functional Design processes. However, only recently the interest is turning to manufacturing and related tasks performed during the production phase, such as Industrial Design of the product, assembly, balancing lines or configuration and change management, among others.

Modelling of manufacturing systems in the aerospace industry has been investigated by some of the authors in recent years [4-6]. Recently, Models for Manufacturing (MfM) has been proposed by the authors as a new approach to apply MBSE concepts to Manufacturing. The novelty of the proposed MfM methodology consists of the development of a reference 3-layer framework based on the definition of a manufac-

adfa, p. 1, 2011.

(c) Springer-Verlag Berlin Heidelberg 2011 
turing ontology and enabling simulation, behaviours and analytical capabilities. The three layers of the framework are referred to as Data Base and Interfaces, Ontology and Software Tools layers. This work focuses on the development of the Ontology layer whereas aspects related to system architecture and methodological approach of MfM are further discussed in [7]. The MfM methodology is still in the preliminary phase.

The MfM methodology is planned to be applied to different manufacturing technologies of interest to the authors' research, such as assembly processes of aeronautical components, CNC machining and metal sheet forming processes. This work presents a preliminary implementation of MfM to an incremental sheet forming process: Single-Point Incremental Forming (SPIF). This novel technology is a flexible and economical manufacturing process with a great potential for the manufacture of small and medium-sized batches of parts with a high degree of customization [8]. SPIF combines several simulation technologies that makes it very attractive to its implementation by MfM, such as CAD/CAM modelling, CNC machine control and analysis of elasto-plastic material behaviour by FEM (Finite Element Method). Furthermore, the research work on SPIF by some of the authors has also motivated the choice of this manufacturing process [9-13]. Next sections briefly introduce the proposed MfM methodology, describe the most relevant aspects of manufacturing by SPIF, present the current state of the SPIF model and discuss the results obtained.

\section{Methodology}

The proposed MfM methodology is supported by a 3-layer framework referred to as Data Base and Interfaces, Ontology and Software Tools layers. The MfM methodology is carried out through the following steps:

1. Create the system scope to define the limits of the model.

2. Define the ontology (Ontology layer).

3. Define behaviour (Software Tools layer).

4. Instance the data bases through the interfaces using the defined ontology (Data Base and Interfaces layer).

The system scope is needed because manufacturing is a large and wide part of the lifecycle and models can cover several topics. The scope clearly establishes the main concepts of the model related to manufacturing activities or functions, materials, equipment, tools, design, modelling, simulation, analysis, etc. It must be approved by all stakeholders before defining the next steps of the system ontology.

The Ontology layer is the core of the 3-layer model and is supported by models that are easy to read, understand, reuse and enrich. It provides the tools and methods necessary to collect knowledge of the manufacturing system. It is defined by the system scope applicable to the model, the data model and semantics itself, and the simulation requirements or behaviours.

The Software Tools layer allows analysing different models and instantiating real cases from models. Its implementation depends on the type of manufacturing model 
and related simulations. Previously, the system scope has already defined the functionalities that should be implemented in this layer and even the tools to be used.

The Database and Interfaces layer is being implemented by PLM solutions to manage all the information related to the models and their use. The proposed methodology aims the use of simple tools that allow to easily write an ontology to discuss with skilled people in a collaborative way.

\section{Single-Point Incremental Forming (SPIF)}

Incremental forming is an innovative sheet forming process that makes use of computers and $\mathrm{CNC}$ technology to plastically deform a raw material through the progressive and local pressure of a small-size forming tool. This technology has been used for the last few years to obtain a variety of industrial parts due to its benefits compared with conventional manufacturing processes, such as non-dedicated equipment requirements, dieless process, flexibility, low costs and improvement of material formability, among others. Many variations of incremental forming have been explored, but by far the most widely used is the single-point incremental forming (SPIF) configuration [8].
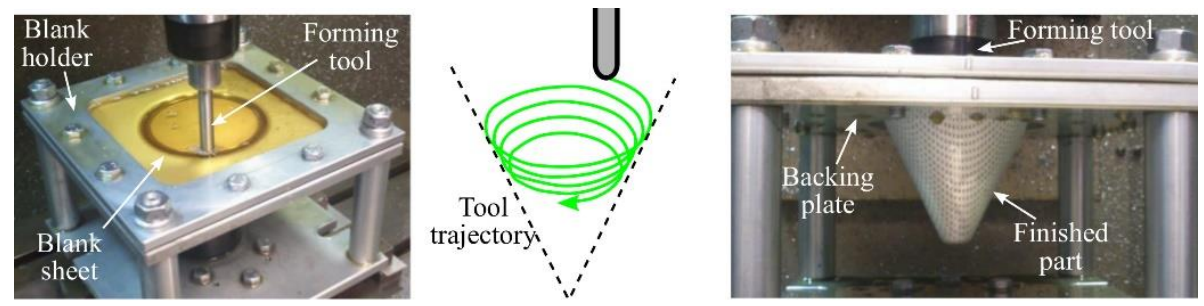

Fig. 1. Basic components to produce a cone by SPIF: (a) recently started process; (b) schema of the tool trajectory; and (c) finished sheet part.

Figure 1 presents the basic components of the SPIF process: the blank sheet, the forming tool, and tools for clamping and holding the sheet in its position (blank holder and backing plate). The backing plate opening defines the maximum working area of the forming tool. The tool trajectory is generated by a CNC machine. The tool action is performed on the front surface of the sheet and there is no backup die supporting the back surface.

SPIF is mainly applied in the automotive and aeronautical sectors, either to obtain functional parts or prototypes, as well as for biomedical prosthesis [9]. Figure 2 shows some CAD models and manufactured parts by SPIF carried out for experiments that demonstrate the viability of the process [10]. Part design as well as tools definition and programming of $\mathrm{CNC}$ code are carried out frequently by conventional machiningbased CAD/CAM systems. Often the SPIF process is decomposed in several forming stages to homogenize deformation. Thus, the design of the forming strategy is a fundamental factor to take into account to produce successful parts using SPIF. 


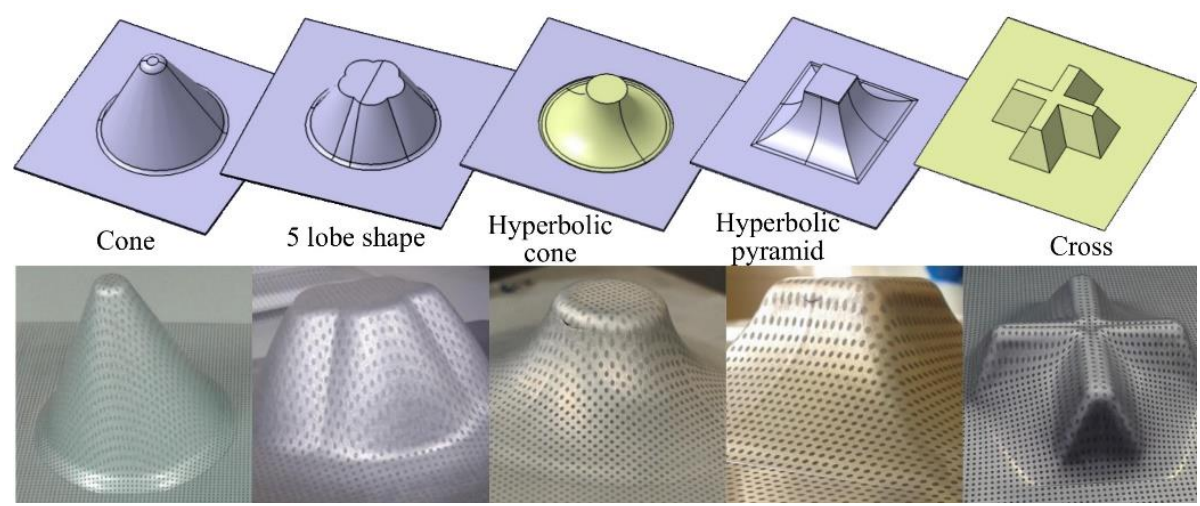

Fig. 2. CAD models and sheet parts manufactured by SPIF.

The design evaluation of the SPIF process is carried out through simulations of both tool movements and material deformation [11]. The former are accomplished by analysing tool trajectories and collisions in the CAD/CAM system. The latter simulations are achieved through numerical studies by finite element analysis (FEA) systems. Figure 3(a) illustrates a numerical simulation of a SPIF process to produce a circular hole-flanged part [12]. Typical objectives of these studies include the calculation of forces and geometrical deviations after elastic spring-back, and the evaluation of sheet failure, among others.
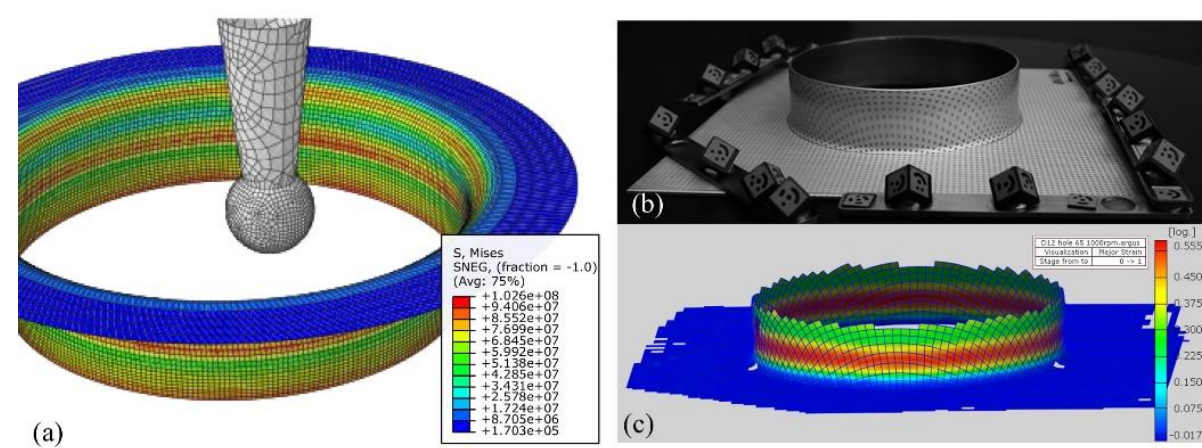

Fig. 3. Analysis of a hole-flanged sheet part manufactured by SPIF: (a) numerical study by FEA; (b) setup for capturing digital images of a manufactured specimen; and (c) analysis of strains by DIC techniques.

Sheet parts manufactured by SPIF are inspected according to the quality and inspection rules of the manufacturing organization. Figure 3(b-c) presents a dimensional inspection of the hole-flanged part using digital image correlation (DIC) techniques [13]. The technique used in this example consisted of marking the sheet with a circle pattern before the forming operation and measuring the strains of resulting ellipses by the DIC software. For pieces rejected by the quality control, manufacturing issues are 
evaluated to find the most appropriate solution which includes modifications on blank sheet, forming tool, holding devices or tool movement strategies.

\section{$4 \quad$ Results}

\subsection{Scope Model}

The Scope model for the SPIF process is developed with IDEF0 [14] diagrams. IDEF0 assists the modeller in identifying what functions are performed (represented as boxes, see Figure 4) and what is needed to perform those functions (labelled arrows) in four categories: inputs, outputs, controls and mechanisms. The main function is Produce Part by SPIF that transforms the input Raw Material into the output Finished and Tested Part, according to controls Part Model and Quality and Inspection Rules, and carried out with mechanisms NC Machine, Forming Tool and Tools. Another relevant mechanism is PLM System that represents software tools used to generate the NC program and analyse the SPIF process. Since the blank sheet, the forming tool and tools are customized to produce each sheet part, their definitions are also modelled as an output SPIF Setup Definition of the main function.

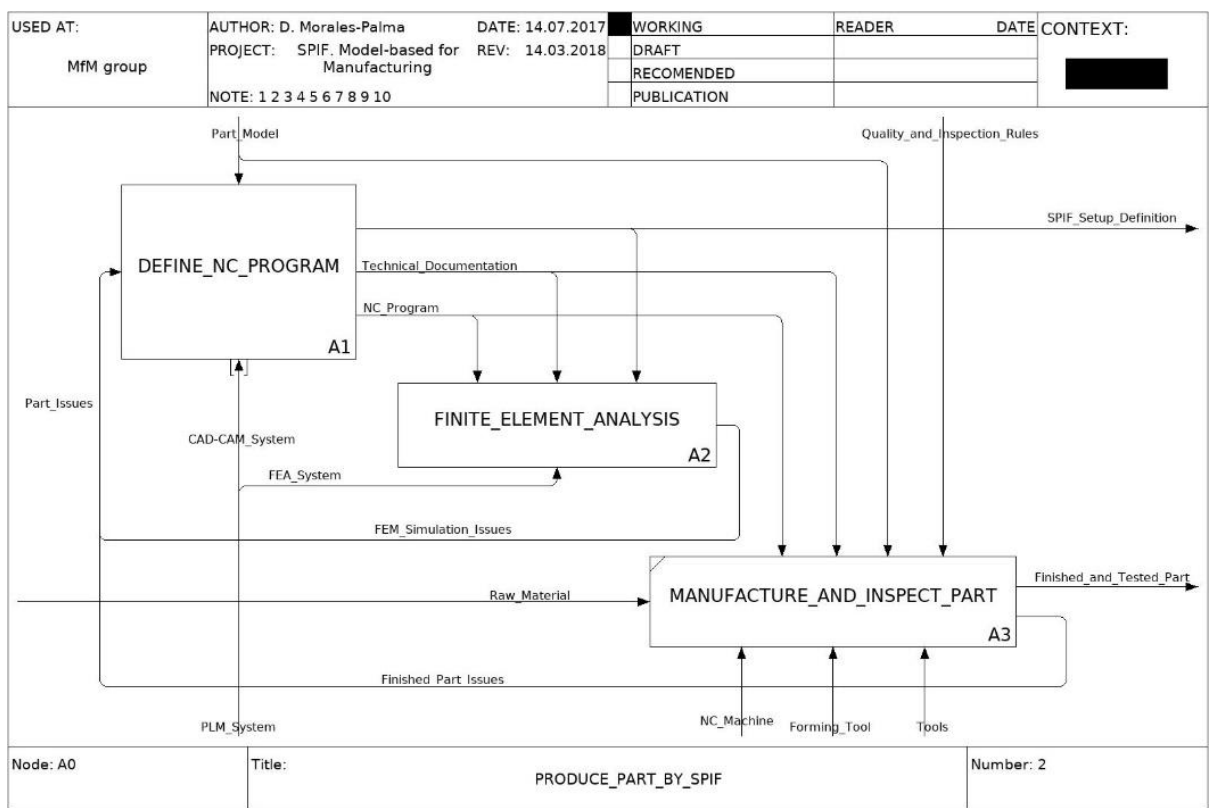

Fig. 4. Scope definition for SPIF with IDEF0 diagrams: Produce a part by SPIF (level A0).

The current Scope model contains many IDEF0 diagrams but only two are shown in this document. Figure 4 displays the decomposition of the main function into three subfunctions that operate simultaneously with each other, while the interface arrows constraining when and how operations are triggered and controlled. For example, Part 
Model is a control element used to Define NC Program and Manufacture and Inspect Part (for inspection) but not to develop Finite Element Analysis (FEA). Part Issues represents all the possible problems predicted by FEA (FEM Simulation Issues) or found when inspecting the part (Finished Part Issues). NC Program and Technical Documentation are generated from Define NC Program which are required to control FEA, manufacturing and inspection of the part.

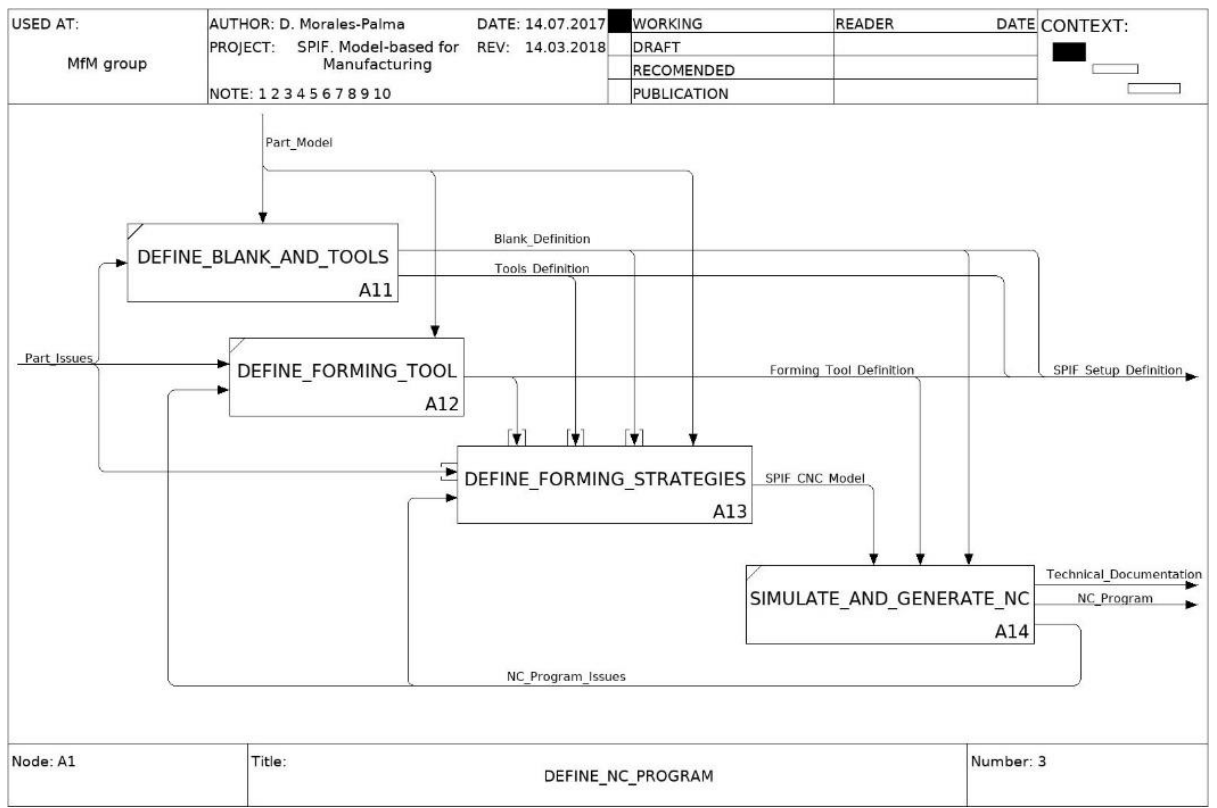

Fig. 5. Scope definition for SPIF with IDEF0 diagrams: Define NC Program (level A1).

Figure 5 represents a lower level IDEF0 diagram to detail function Define NC Program. As can be seen, Part Model is used to Define Blank and Tools, Define Forming Tool and Define Forming Strategies using a CAD/CAM System (note that this mechanism is "tunnelled" in Figure 4 as represented as a snippet of the arrow in brackets, which means that is a mechanism element for all subfunctions). The function Define Forming Strategies generates a SPIF CNC Model that contains decisions about number of stages and geometry of manufactured parts between stages, as described in a lower level IDEF0 diagram. The SPIF CNC Model is used to Simulate and Generate $N C$ with the CAD/CAM system. Figure 5 also shows that if NC Program Issues occurs, they must be resolved by modifying the definition of forming tool or forming strategies.

From the Scope model, IDEF0 "inputs" and "outputs" are used as main classes of the ontology whereas "functions" and "mechanisms" will be used to implement the Software Tools layer. However, a "control" element can be either an ontology class, as is Part Model (see Figures 4 or 5), or an object for the Software Tools layer, as is Quality and Inspection Rules (see Figure 4). In the current system prototype, a tag has been added to IDEF0 element names to allow the system to recognize the ontology 
classes from those that are not. This tag has been removed from this document for clarity. Nevertheless, this solution is provisional and will be replaced by a more functional one in future developments.

Once the Scope model is finished and approved by the work team, the IDFE $\varnothing$ model can be uploaded to the system (in IDL format) and converted to an OWL document containing the main classes of the ontology. This document can be downloaded and opened with IHMC CMapTools software to define the Data Model as a concept map.

\subsection{Data Model}

A concept map or conceptual diagram is a graphical tool for structuring and representing knowledge. In the proposed methodology, the modeller organizes the concepts or main classes (represented as boxes, see Figure 6) in a hierarchical structure, creates relationships between concepts (as labelled arrows) and enriches the concept map by adding new concepts and attributes.

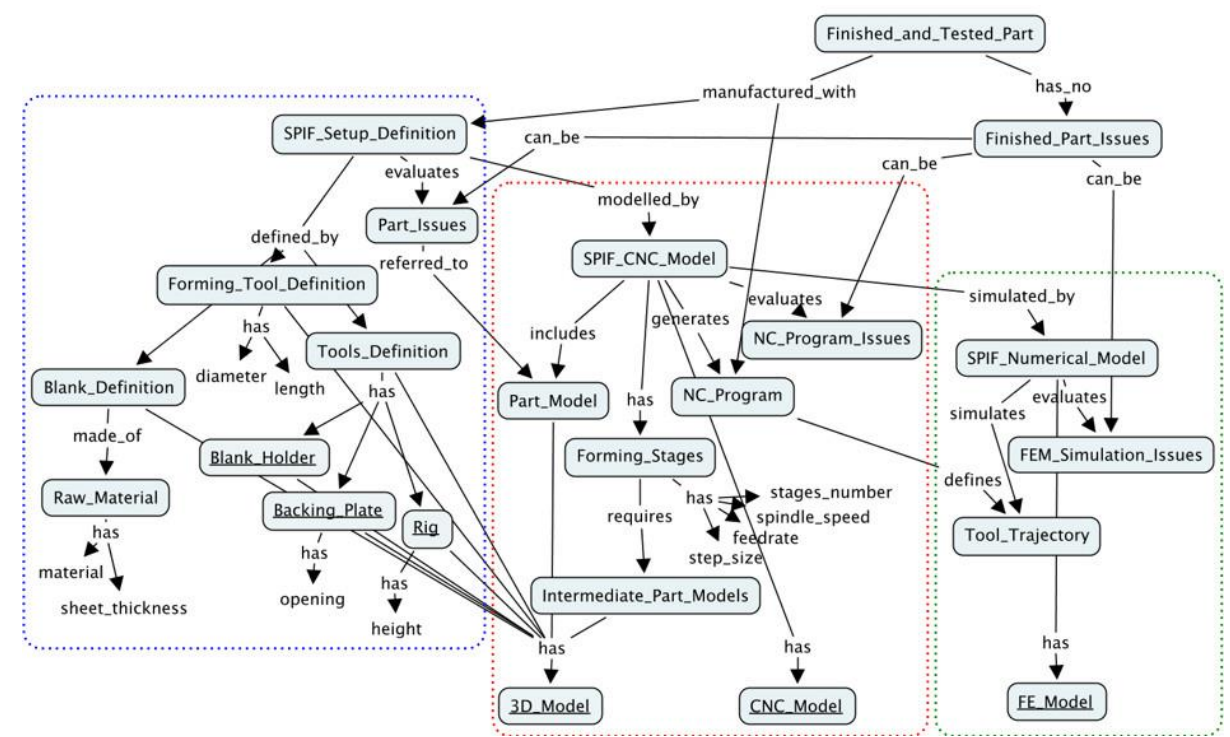

Fig. 6. Ontology definition for SPIF with concept maps.

Figure 6 depicts the concept map for the SPIF process. The focus question is: "How is a sheet part produced by SPIF?" The most general concepts are at the top of the diagram and can be described as follows: the Finished and Tested Part is manufactured with the SPIF Setup Definition and the NC Program and, given that the part has been already tested, it has no Finished Part Issues; the SPIF Setup Definition is modelled by a SPIF CNC Model in order to generate the NC Program; and the Finished Part Issues can be of different type: Part Issues, NC Program Issues or FEM Simulation Issues. 
The concept map elements in Figure 6 have been arranged inside dotted boxes to highlight three fields of knowledge of the proposed ontology. The former represents the definition of physical components of the SPIF Setup Definition: blank, forming tool, etc. The second group depicts the SPIF CNC Model to be developed in a $\mathrm{CAD} / \mathrm{CAM}$ system to design the SPIF process and generate the NC Program. The latter represents the SPIF Numerical Model to simulate the Tool Trajectory and analyse the SPIF process in a FEA system to overcome any FEM Simulation Issue.

In the proposed methodology, a secondary class of the Data model is a class added to the concept map that was not included in the Scope model. Some secondary classes have been added to the concept map for SPIF to illustrate this concept, represented as boxes with underlined name in Figure 6. For example, Blank Holder, Backing Plate and Rig were included as "children" of Tools Definition, see the lower left corner of Figure 6. Actually, whether these classes are primary or secondary depends on the degree of detail of the Scope model. Indeed, the above secondary classes would be primary if the IDEF0 element Tools Definition of the Scope model would be decomposed into Blank Holder, Backing Plate and Rig in a similar way that SPIF Setup Definition (see Figure 5) was decomposed into Blank Definition, Tools Definition and Forming Tool Definition in order to be related with different IDEF0 functions.

A valuable feature of the proposed methodology is the reuse of other ontologies, already existing or to be developed. The relationship between classes of the proposed ontology for SPIF and classes of other ontologies is implemented through secondary classes in the concept map. For instance, the following secondary classes in Figure 6 aim to fulfil this purpose: $3 D$ Model and CNC Model represent the CAD and CAM models of CAD/CAM systems, respectively, and FE Model is used by FEA systems. The related ontologies as well as the data type of class attributes (integer, string, etc.) are set at a later stage of the proposed methodology. Class attributes are represented as simple labels at the end of arrows in Figure 6.

\section{Conclusions}

A new methodology based on a 3-layer architecture has been proposed for modelling manufacturing systems. In this work the methodology has been applied to an innovative incremental sheet forming (SPIF) and the development of both system scope and ontology has been presented.

It can be concluded that designing the system scope model among all project participants is an efficient method to establish the starting point for development of both Ontology and Software Tools layers. Furthermore, the combination of more than one modelling technique allows to define a more robust ontology from different perspectives. In this work, IDEF0 diagrams and concept maps have been used to define a successful ontology for SPIF. Nevertheless, the proposed methodology is not limited to these two schemes of knowledge representation and could be replaced by others more suitable in future developments.

The current project is still under development and further work is required to evaluate the success of the proposed methodology. Future work includes the implementa- 
tion of the Software Tools layer, the instantiation of real cases from the ontology model and the investigation of alternatives to computer modelling tools.

\section{Acknowledgement}

The authors would like to thank Ignacio Eguía, Jose Carlos Molina, Andrés Padillo and other Sevilla University colleagues, Julio Ortegón and other Cádiz University colleagues, Rebeca Arista, Tamara Borreguero and other AIRBUS colleagues, for their support and contribution during the development of this work.

\section{$7 \quad$ References}

1. Ramos, A.L., Ferreira, J.V., Barceló, J.: Model-Based Systems Engineering: An Emerging Approach for Modern Systems. IEEE Transactions on Systems, Man, and Cybernetics, Part C (Applications and Reviews) 42(1), 101-111 (2012). doi: 10.1109/TSMCC.2011.2106495

2. Holland, O.: Model-Based Systems Engineering. In: Loper M. (eds) Modeling and Simulation in the Systems Engineering Life Cycle. Simulation Foundations, Methods and Applications. Springer, London (2015). doi: 10.1007/978-1-4471-5634-5_23

3. D'Ambrosio, J., Soremekun, G.: Systems engineering challenges and MBSE opportunities for automotive system design. In: 2017 IEEE International Conference on Systems and Cybernetics (SMC), p. 2075, Banff, AB, Canada (2017). doi: 10.1109/SMC.2017.8122925

4. Gómez, A., Ríos, J., Mas, F., Vizán, A.: Method and software application to assist in the conceptual design of aircraft final assembly lines. J. Manuf. Systems 40, 37-53 (2016). doi: 10.1016/j.jmsy.2016.04.002

5. Mas, F., Rios, J., Menendez, J.L., Gomez, A.: A process-oriented approach to modeling the conceptual design of aircraft assembly lines. Int. J. Adv. Manuf. Technol. 67(1-4), 771-784 (2013). doi: 10.1007/s00170-012-4521-5

6. Mas, F., Oliva, M., Ríos, J., Gómez, A., Olmos, V., García, J.A.: PLM Based Approach to the Industrialization of Aeronautical Assemblies. Proc. Engng. 132, 1045-1052 (2015). doi: 10.1016/j.proeng.2015.12.594

7. Mas, F., Racero, J., Oliva, O., Morales-Palma, D.: A preliminary methodological approach to Models for Manufacturing (MfM). In: 18th International Conference on Product Lifecycle Management, PLM18 (2018). (In press)

8. Behera, A.K., Sousa, R.A., Ingarao, G., Oleksik, V.:Single point incremental forming: An assessment of the progress and technology trends from 2005 to 2015. J. Manuf. Proc. 27, 37-62 (2017). doi: 10.1016/j.jmapro.2017.03.014

9. Centeno, G., Morales-Palma, D., Gonzalez-Perez-Somarriba, B., Bagudanch, I., EgeaGuerrero, J.J., Gonzalez-Perez, L.M., García-Romeu, M.L., Vallellano, C.: A functional methodology on the manufacturing of customized polymeric cranial prostheses from CAT using SPIF. Rapid Prot. J. 23(4), 771-780 (2017). doi: 10.1108/RPJ-02-2016-0031

10. Morales-Palma, D., Martínez-Donaire, A.J., Centeno, G., Vallellano, C.: Teaching Experience for the Virtualization of Machine Tools and Simulation of Manufacturing Operations. Mater. Sc. Forum 853, 79-84 (2016). doi: 10.4028/www.scientific.net/MSF.853.79

11. Centeno, G., Martínez-Donaire, A.J., Bagudanch, I., Morales-Palma, D., Garcia-Romeu, M.L., Vallellano, C.: Revisiting Formability and Failure of AISI304 Sheets in SPIF: Ex- 
perimental Approach and Numerical Validation. Metals 7, 531 (2017). doi: $10.3390 /$ met7120531

12. Morales-Palma, D., Borrego, M., Martínez-Donaire, A.J., Centeno, G., Vallellano, C.: Preliminary investigation on homogenization of the thickness distribution in hole-flanging by SPIF. Proc. Manuf. 13, 124-131 (2017). doi: 10.1016/j.promfg.2017.09.101

13. Borrego, M., Morales-Palma, D., Martínez-Donaire, A.J., Centeno, G., Vallellano, C.: Experimental study of hole-flanging by single-stage incremental sheet forming. J. Mater. Proc. Techn. 237, 320-330 (2016). doi: 10.1016/j.jmatprotec.2016.06.026

14. NIST: Integration Definition for Function Modeling (IDEF0). Computer Systems Laboratory of the National Institute of Standards and Technology, December 1993. http://www.idef.com/wp-content/uploads/2016/02/idef0.pdf [Accessed March 2018]. 